\title{
Ultrasound Images Associated with Snakebites in a Japanese Black Calf
}

\author{
Yasuhiro Morita ${ }^{1,2 *}$, Sadamu Sugiyma ${ }^{3}$ and Takeshi Tsuka ${ }^{4}$ \\ ${ }^{1}$ Department of Animal Sciences, Graduate School of Bioagricultural Sciences, Nagoya University, Furo-cho, Chikusa-ku, Nagoya, Japan \\ ${ }^{2}$ Asian Satellite Campuses Institute, Nagoya University, Furo-cho, Chikusa-ku, Nagoya, Japan \\ ${ }^{3}$ Maniwa Veterinary Clinic, Okayama P.F.A.M.A.A, 794-1 egawa, Maniwa-city, Okayama, Japan \\ ${ }^{4}$ Department of Veterinary Clinical Medicine, School of Veterinary Medicine, Tottori University, Koyama- Minami, Tottori-city, Tottori, Japan
}

*Corresponding author: Yasuhiro Morita, Department of Animal Sciences, Graduate School of Bioagricultural Sciences and Asian Satellite Campuses Institute, Nagoya University, Furo-cho, Chikusa-ku, Nagoya 464-8601, Japan, E-mail: ymorita@agr.nagoya-u.ac.jp

Received: 26 Mar, 2019 | Accepted: 09 Apr, 2019 | Published: 17 Apr, 2019

Citation: Morita Y, Sugiyma S, Tsuka T (2019) Ultrasound Images Associated with Snakebites in a Japanese Black Calf. J Anim Sci Res 3(2): doi dx.doi. org/10.16966/2576-6457.127

Copyright: (C) 2019 Morita Y, et al. This is an open-access article distributed under the terms of the Creative Commons Attribution License, which permits unrestricted use, distribution, and reproduction in any medium, provided the original author and source are credited.

\section{Abstract}

Snakebites are one of the leading causes of severe tissue necrosis in animals. Snakebite injuries can be diagnosed by their two distinct scars caused by the fangs. However, these wounds are rarely found in cattle because of their physical character. Therefore, the accumulation of an objective assessment, such as images diagnosis, in cattle is necessary. In this case, a 6-month-old male Japanese black calf showed sudden anorexia and swelling of the mandible; the animal died eight days after the onset of symptoms. On Day 1, the mandibular swelling was observed and body temperature was recorded as $41.5^{\circ} \mathrm{C}$, and ptyalism was noted. The calf showed progressive swelling of the jaw and the dewlap. On Day 8 , the calf was unconscious and died and a simplified necropsy was performed. The laboratory tests did not reveal any organ dysfunction or sepsis. Ultrasonography revealed subcutaneous edema, a cobblestone appearance characteristic of cellulitis and detachment between the subcutaneous and muscle tissue layers. The ultrasound imaging provided a diagnosis of cellulitis accompanied by necrosis of the deep fascial layer and also revealed detachment between the subcutaneous tissue and the muscle tissue with rapid enlargement of the affected area. Moreover, a subsequent necropsy proved that there was severe necrosis from the subcutaneous tissue to the fascia. The changes in the subcutaneous tissues were confirmed by simplified necropsy, and in this case were diagnosed as necrotizing cellulitis. The ultrasound images were able to provide the same diagnosis as the necropsy findings, which suggest that ultrasound imaging is valuable for the diagnosis of snakebite wounds in cattle. This case report provides valuable clarification about the use of ultrasound imaging of snakebites in cattle and ultrasonography could provide the essential information needed to diagnose and treat the animal.

Keywords: Cow; Image diagnosis; Snakebite; Ultrasonography

\section{Introduction}

Hundreds of thousands of people are envenomed and tens of thousands are killed or injured by snakes throughout the world every year [1]. Snake envenomation in domestic animals also occurs frequently $[2,3]$ and has been reported in dogs [4,5], cats [6,7], horses [8,9], sheep [10,11], and cattle [12]. Snakebite injuries can be diagnosed by their appearance in small animals such as dogs and cats because of the two distinct scars caused by the fangs. However, these wounds are rarely found in cattle due to their thick skin, hair coats, and quantity of subcutaneous fat [13]. Therefore, snakebites may be undiagnosed in many cases.

In Japan there are two common venomous snakes. The Japanese pit viper (Mamushi, Gloydius blomhoffii) is one of the most common venomous snakes in Japan [14], belonging to the family Viperidae and sub-family Crotalinae (pit vipers). A habitat of Japanese pit viper is in areas between $30^{\circ} \mathrm{N}$ and $46^{\circ} \mathrm{N}$ and the another common one (Habu, Yellow-spotted pit viper, Protobothropsflavoviridis) is on only Okinawa
Island and the surrounding isolated islands in $24^{\circ} \mathrm{N}$ to $29^{\circ} \mathrm{N}$ [14]. The venomous snakes of this family as well as Crotalidae and Colubridae are predominantly hemotoxic, and their bites generally cause local pain, swelling, edema and oozing of blood from the site of impact $[13,15]$. Some cases may result in the animal's death. Snakebites, as well as other animal bites, cause severe soft tissue infections, such as necrotizing soft tissue infections (NSTIs) which are characterized by extensive, rapidly progressing soft tissue necrosis [16].

Ultrasonography is a convenient, sensitive and specific tool for quick diagnosis in even difficult situations. It can provide accurate information for emergency physicians when diagnosing NSTIs in humans [17]. There have been few reports in cattle or other ruminants about the use of ultrasonography for snake and other animal bites, despite many incidences in small animals. Therefore, the accumulation of ultrasound images in cattle and other livestock animals is necessary and would benefit the species. In the present case, a mandibular swelling, thought to be a snakebite wound was 
observed and eventually confirmed by ultrasonographic examination and necropsy. This case suggests the validity of ultrasound imaging for necrotic wounds such as snakebite injuries in cattle.

\section{Case History}

A 6-month-old male Japanese black calf showed sudden anorexia and swelling of the mandible; the animal died eight days after the onset of symptoms. The clinical findings are described below (Table 1). On Day 1, the mandibular swelling was observed (Figure 1A), but there were no structural abnormalities or injuries in the oral cavity. Body temperature was recorded as $41.5^{\circ} \mathrm{C}$, and ptyalism was noted (Figure 1B). The owner saw a mamushi at front of the paddock in this case although he had not seen the situation that the mamushi bit the calf, and more he saw at near the paddock on several occasions. Therefore, we diagnosed the wound caused by the snakebites tentatively. The calf was treated with antibiotics (Mycillin, Streptomycin [12,500 $\mu \mathrm{g} / \mathrm{kg}]$ and benzylpenicillin [10,000 IU/kg], Meiji-seika Co., Tokyo, Japan, Cefazolin [10 mg/kg], Fujita Pharmaceutical Co., Ltd., Tokyo, Japan and Ceftiofur [5 mg/kg], Zoetis, Inc., New Jersey, United States) for 7 days and steroids (Dexamethasone sodium phosphate $[0.01 \mathrm{mg} / \mathrm{kg}]$, Nippon Zenyaku Kogyo Co., Ltd., Koriyama, Japan) for 4 days, and on Day 5, the steroid drug replaced to antihistamines drugs (LADON, Diphenhydramine $[0.5 \mathrm{mg} / \mathrm{kg}]$, methylephedrine $[0.5 \mathrm{mg} / \mathrm{kg}]$ and caffein $[0.75 \mathrm{mg} / \mathrm{kg}]$, Nippon Zenyaku Kogyo Co., Ltd., Koriyama, Japan). Despite this, the calf showed progressive swelling of the jaw and the dewlap, and severe facial edema. On Day 8, the calf was unconscious and died during the ultrasound exam. Only simplified necropsy was performed under the permission of the owner. The result provided us differential diagnosis that the case was caused by the snakebites.

\section{Clinical Examination Results}

Laboratory tests were performed on Days 1 and 7. On Day 1, there was no evidence of renal failure or liver dysfunction (blood urea nitrogen $[\mathrm{BUN}$ ], $15.8 \mathrm{mg} / \mathrm{dL}$, creatinine [Cre], $1.06 \mathrm{mg} / \mathrm{L}$, aspartate aminotransferase [AST], $49 \mathrm{IU} / \mathrm{L}, \gamma$-glutamyl transferase [GGT], 21 IU/L). On Day 7, rhabdomyolysis and renal failure were not observed (creatine kinase [CK], $419 \mathrm{U} / \mathrm{L},[\mathrm{BUN}], 13.3 \mathrm{mg} / \mathrm{dL}$, [Cre], $0.7 \mathrm{mg} / \mathrm{L}$ ). Moreover, sepsis was not expected (white blood cell count, 4600 $\mu / \mathrm{L}$, blood platelet count, $65 \times 10^{4} \mu / \mathrm{L}$ ). Dehydration was evident by hemoconcentration (hematocrit value [Hct], 44.1\%, and total albumin [Alb], $2.6 \mathrm{~g} / \mathrm{dL}$ ).

While standing, the animal was examined with a portable ultrasonographic device (HS-101V, Honda Electronics Co., Ltd., Toyohashi, Japan) using a linear probe $(5 \mathrm{MHz})$ on Days 1,5 and 8. On Day 1 , the examination of the swollen mandibular surface revealed echogenic fibrous structures surrounded by comparatively echogenic and homogeneous fluid approximately $1 \mathrm{~cm}$ deep to the facial surface (Figure 2A). The deeper subcutaneous tissues included heterogeneously echogenic structures, in which small accumulations of the hypoechoic fluid were scattered throughout the subcutaneous tissues. On Day 8, the structure of the subcutaneous tissues was unrecognizable except for the approximately $1 \mathrm{~cm}$-thick superficial echogenic layers and was replaced with a hypoechoic fluid in the space between the superficial subcutaneous layers and the muscle tissues (Figure 2B). The appearance of the muscle layer and the fascia was normal. The fluid contained significant purulent exudate.

We could not obtain the owner's consent for a pathological necropsy despite offering informed consent in detail. Instead, we conducted a simplified necropsy, which consisted of only macroscopic examination. The necropsy confirmed severe necrosis from the subcutaneous tissue to the fascia. Two wounds observed about 2.5 $\mathrm{cm}$ apart on the cervical skin were consistent with snakebite (Figure $3 \mathrm{~A}$ ). The necrosis of the subcutaneous tissue layer extended over the pharynx (Figure 3B). A fistula leading to the pharynx filled with hemorrhagic, purulent exudate was observed. Moreover, significant numbers of Trueperella pyogenes organisms were isolated from the fluid and affected area by previously reported protocol from reports by Ishiyama, et al. and Merlino, et al. [18,19]. The bacterium was identified by simple visual detection on two well chromogenic and blood agar plates (CHROMagar Orientation and 5\% sheep blood agar plate, KANTO CHEMICAL CO., INC., Tokyo, Japan).

\section{Discussion}

On Day 1, the animal lost its appetite suddenly due to a mandibular swelling. The animal was treated with streptomycin and dexamethasone. Its vigor and ruminal motility were acceptable for the treatment with the corticosteroid, although the ultrasound revealed suspicious cellulitis. Dexamethasone is a useful drug for treatment of edema and also has the potential to alleviate the symptoms of wound infections $[20,21]$. In this case, although the situation provided the tentative diagnosis as the venomous snakebites case on day 1 , antivenoms and a tetanus toxoid vaccine were avoided due to potential complications, including fatal anaphylactic shock [22,23]. The calf had vigor and ruminal motility, therefore the animal was treated without those drugs. On Day 2, the swollen region expanded to the dewlap and the lethargy and anorexia progressed. The antibiotics were switched to cefazolin, a cephem-based antibiotic with strong efficacy against Gram-positive bacteria, which are frequently isolated from wound infections in cattle. On Day 5, steroid administration was discontinued as the swelling of the lower jaw and dewlap region gradually subsided and the animal had a bit more vigor and appetite. However, on Day 6, severe edema stretching from the lower jaw to the dewlap recurred. Cefazolin was then replaced by ceftiofur, which is useful for contaminated wounds such as foot rot [24]. Unfortunately, on Day 8 , the animal died. Though we speculated the cause of death to be dyspnea secondary to aspiration, the necropsy revealed that necrosis of the pharynx filled with hemorrhagic, purulent exudate led to the death of the calf.

The venoms of the family of Crotalinae especially can cause local tissue damage, paralysis of a nerve, systemic hemorrhages and myotoxicity, acute renal failure, or complex symptom of these. In this case, no renal failure, liver dysfunction, or sepsis from the poisoning was observed. This is likely because $50 \%$ of snakebites are dry bites, meaning no venom is injected [25]. In many cases, severe subcutaneous soft tissue infections such as NSTIs are often the result by dry bites by animals, including snakes [26]. The definitive diagnosis requires the detection of snake venom despite specialized examination of livestock animals.

Cellulitis is a common form of soft tissue infection, especially in the cases of animal bites. The ultrasound findings of cellulitis vary according to the site and severity of infection. In general, cellulitis is characterized to including a spread of the swollen region, increasing echogenicity of subcutaneous tissues. Cellulitis reveals a variable appearance like a cobblestone (it's called a cobblestone sign) depending on the amount of fluid around the fascia, the degree of subcutaneous edema [27]. In this case, the ultrasound revealed the cobblestone appearance on Day 1 and Day 5. On Day 8, the ultrasound also revealed detachment between the subcutaneous tissue and the muscle tissue with rapid enlargement due to inflammation of the affected area. The results of ultrasound imaging were consistent with cellulitis accompanied by necrosis of the deep fascial layer. Thus, ultrasonography could provide the essential information needed to diagnose and treat the animal. 


\begin{tabular}{|c|c|c|c|c|c|c|c|c|c|c|c|c|}
\hline$\infty$ & $\stackrel{\pi}{\leq}$ & $\stackrel{\pi}{\underline{\pi}}$ & $\stackrel{\pi}{\Omega}$ & 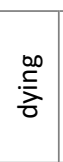 & 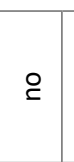 & $\stackrel{\circ}{\check{1}}$ & 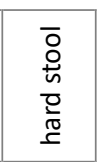 & 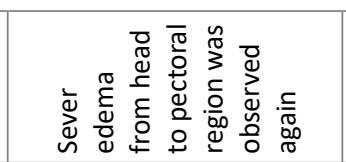 & 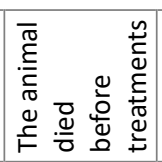 & $\stackrel{\pi}{\geq}$ & $\stackrel{\pi}{\geq}$ & $\stackrel{\pi}{\underline{x}}$ \\
\hline$\wedge$ & 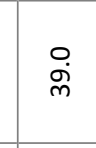 & $\infty$ & $\stackrel{\infty}{m}$ & 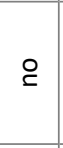 & 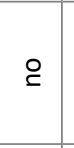 & $\stackrel{\circ}{\check{1}}$ & 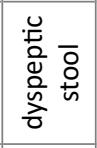 & 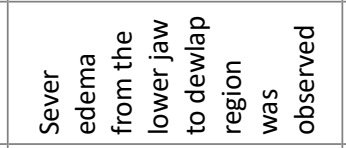 & 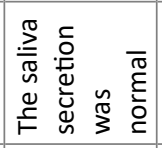 & 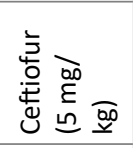 & $\stackrel{\circ}{\check{1}}$ & 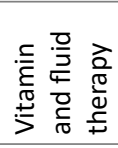 \\
\hline 0 & $\stackrel{\sim}{a}$ & $\stackrel{\infty}{\circ}$ & ஸ & 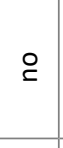 & 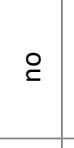 & $\vec{v}$ & 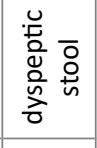 & 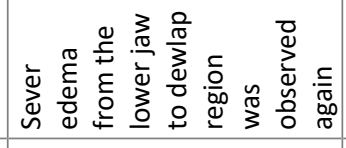 & 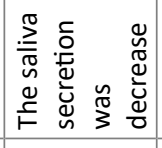 & 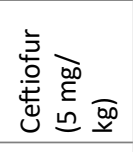 & $\stackrel{\circ}{\varrho}$ & 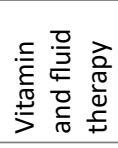 \\
\hline$\stackrel{n}{\stackrel{n}{\Xi}}$ & 今े & 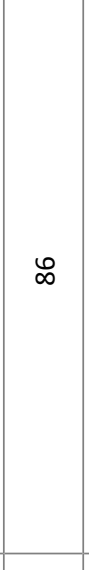 & q & 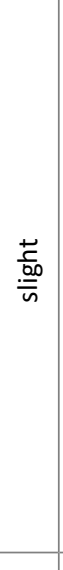 & 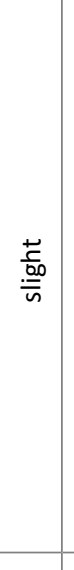 & $-r$ & 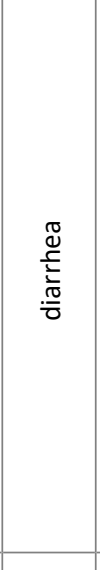 & 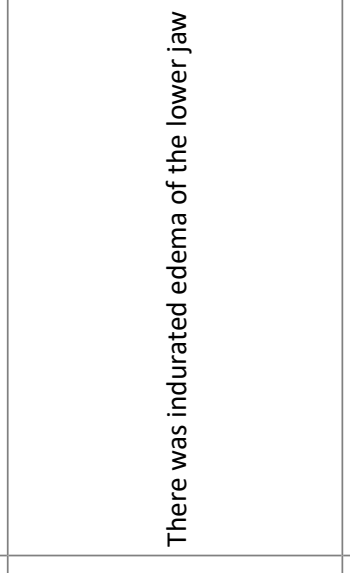 & 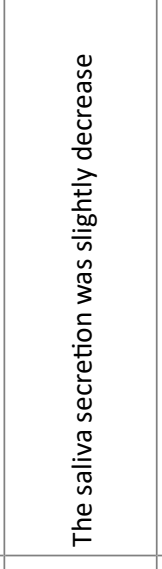 & 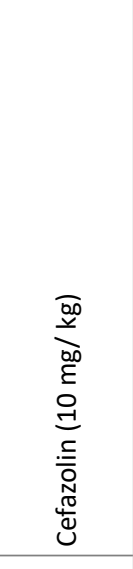 & 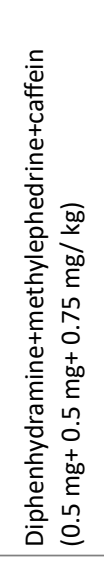 & 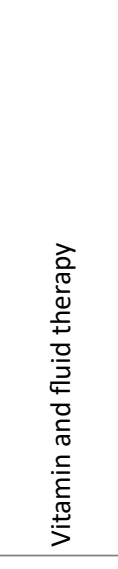 \\
\hline$\sigma$ & 요 & ৪ & $\stackrel{\infty}{m}$ & 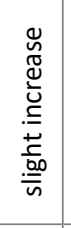 & 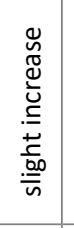 & $\vec{v}$ & 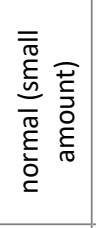 & 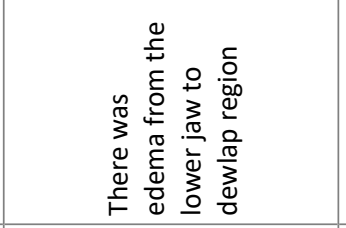 & 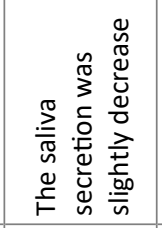 & 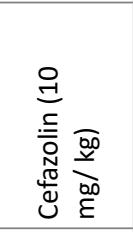 & 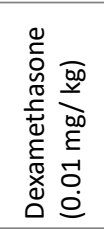 & 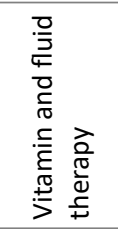 \\
\hline$m$ & $\stackrel{+}{\circ}$ & $\stackrel{\infty}{\curvearrowleft}$ & $\stackrel{\infty}{q}$ & ؟ & $\stackrel{\circ}{9}$ & $\vec{v}$ & 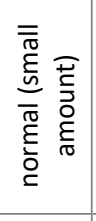 & 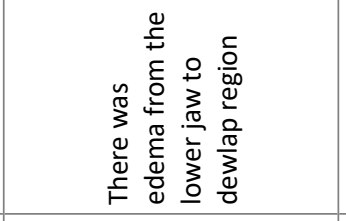 & 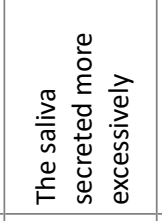 & 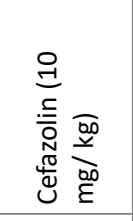 & 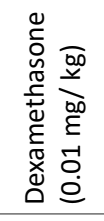 & 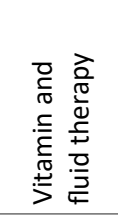 \\
\hline$N$ & $\stackrel{0}{\vec{y}}$ & $\stackrel{\infty}{\curvearrowleft}$ & $\stackrel{\infty}{n}$ & 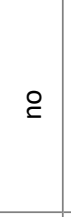 & $\stackrel{\circ}{9}$ & $\vec{v}$ & 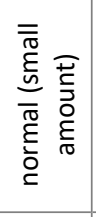 & 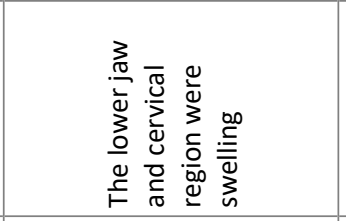 & 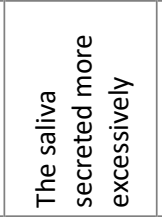 & 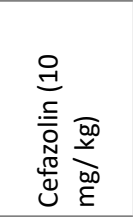 & 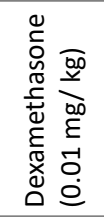 & 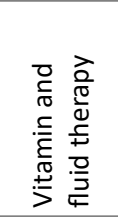 \\
\hline$r$ & $\stackrel{\text { nn }}{\vec{f}}$ & ঃ) & $\mathscr{\ell}$ & 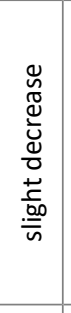 & 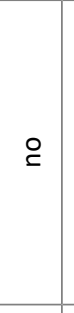 & $\rightarrow$ & 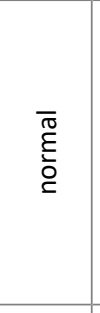 & 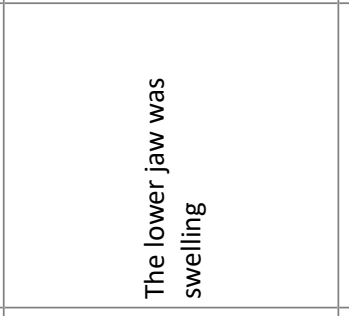 & 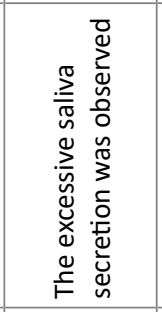 & 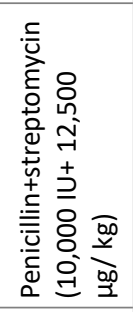 & 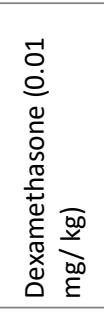 & 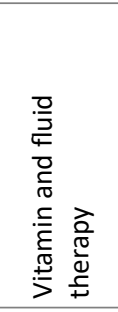 \\
\hline 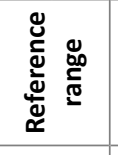 & 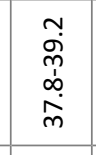 & 空 & $\begin{array}{l}\text { ஸे } \\
\text { ’े }\end{array}$ & & & $\stackrel{I}{I}$ & & & & & & \\
\hline 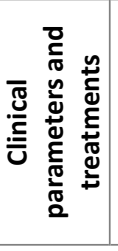 & 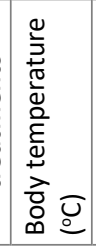 & 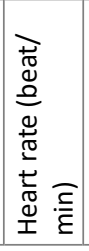 & 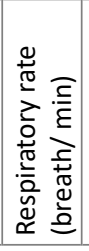 & 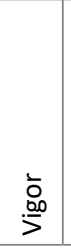 & 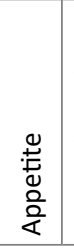 & 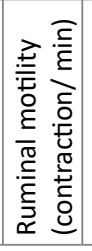 & $\begin{array}{l}\overline{\mathrm{o}} \\
\text { in }\end{array}$ & 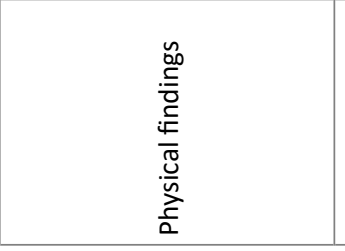 & 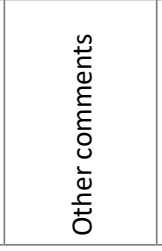 & 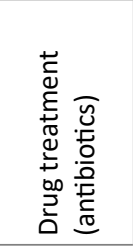 & 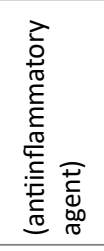 & 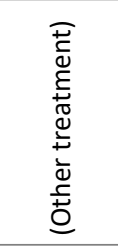 \\
\hline
\end{tabular}




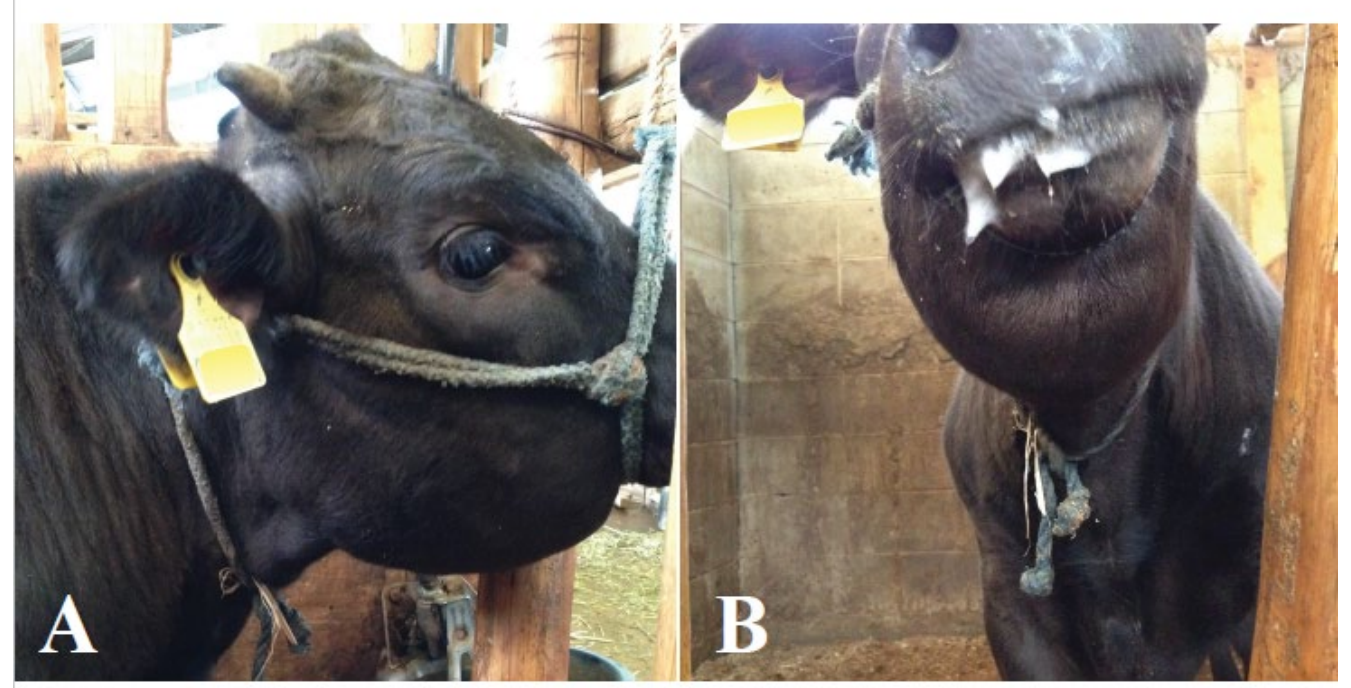

Figure 1: The animal had swelling of the lower jaw (A) and ptyalism was observed (B).

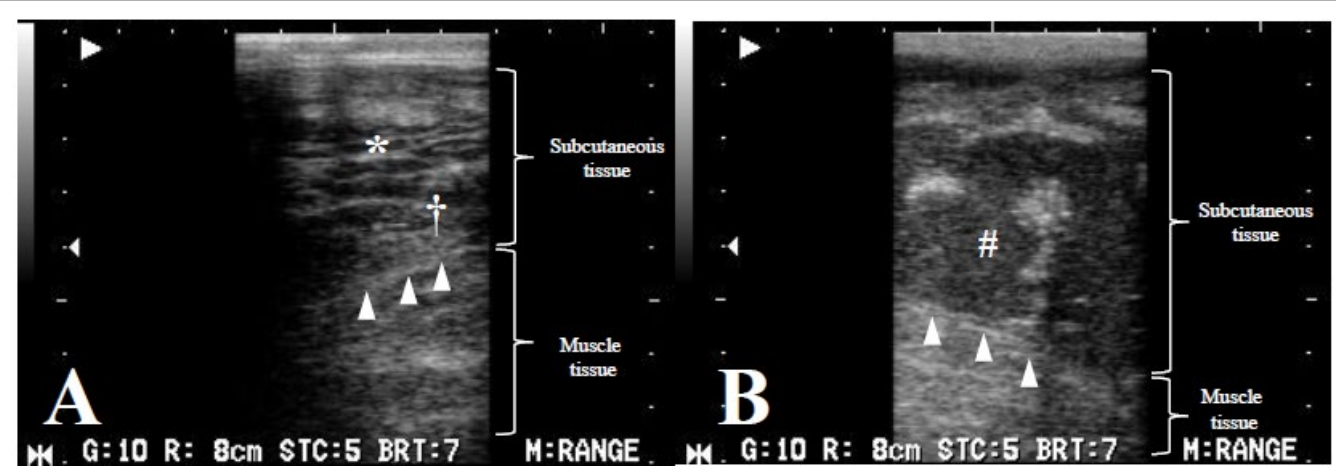

Figure 2: Images from Day 1 with a cobblestone appearance $\left(^{*}\right)$ characteristic of cellulitis, seen here as fluid surrounding highly echogenic structures and hyperechogenicity of the subcutaneous tissue with some degree of hypoechoic fluid $(\dagger)(A)$. On Day 8 , imaging showing separation between the subcutaneous tissue and the muscle tissue with hyperechoic fluid depots (\#) (B). On Day 8, the fascia (arrowhead) was observed definitely (B) compared with the image on Day 1 (A) because the subcutaneous tissue was replaced with a hypoechoic fluid.

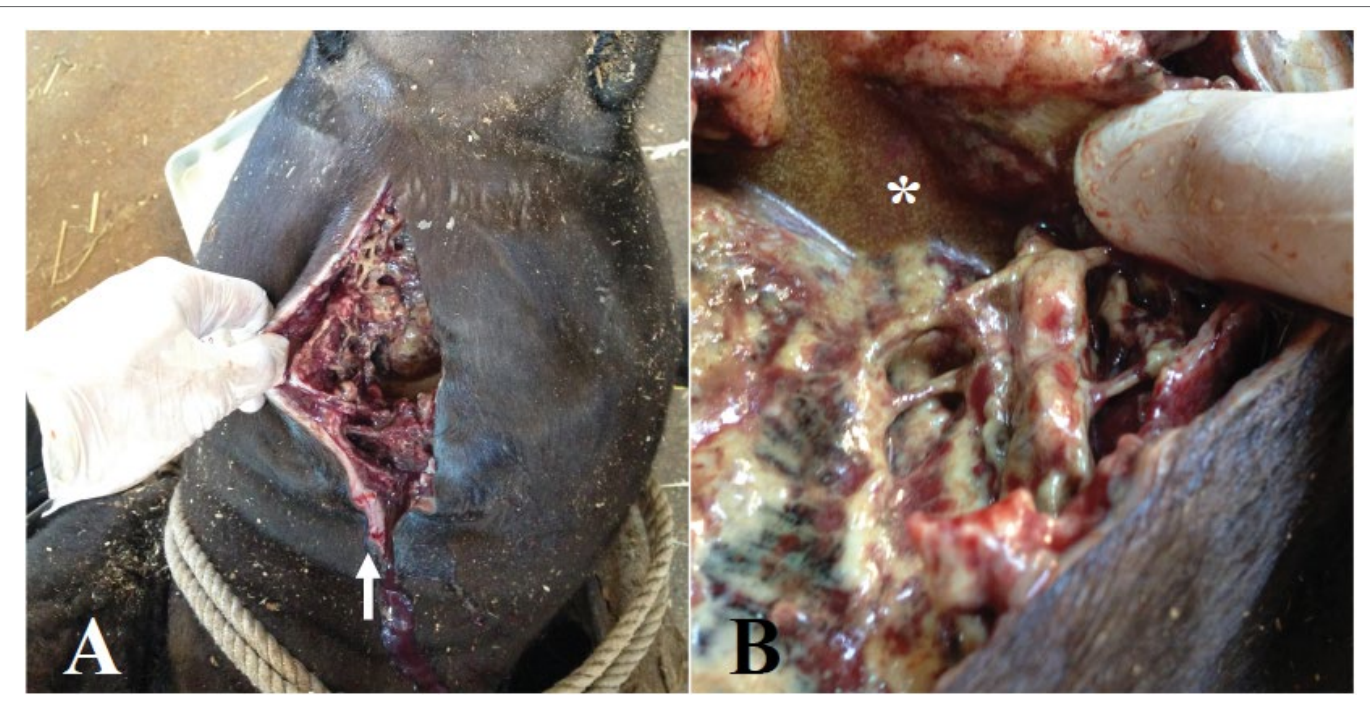

Figure 3: Wounds about $2.5 \mathrm{~cm}$ apart on the cervical skin that were possibly snakebites (arrow) were observed (A). Necrosis of the subcutaneous tissue layer and the surface of the fascia with hemorrhagic, purulent exudate $\left(^{*}\right)$ were observed (B). 
The changes in the subcutaneous tissues were confirmed by simplified necropsy, and in this case were diagnosed as necrotizing cellulitis. The most important diagnostic feature of NSTIs is the identification of the subcutaneous tissues or fascial planes [28]. Ultrasound in humans is imperative for identification of subcutaneous tissue and fascial planes when a wound requires surgical intervention. In this calf, $T$. pyogenes was isolated in large numbers from the affected area. T. pyogenes was renamed [29] and is a common Grampositive bacteria implicated in mastitis, abscesses, pneumonia, and lymphadenitis in many domestic animals [30]. It is probable that $T$. pyogenes is responsible for the necrotizing cellulitis seen in this case. Similarly, Bancroft-Hunt, et al. reported necrotizing fasciitis in a bull due to infection with $A$. haemolyticum, which is closely related to $T$. pyogenes [31].

\section{Conclusion}

We speculate that a Japanese pit viper is responsible for the symptoms that developed in this calf. This case exhibited ultrasound findings characteristic of Japanese pit viper bite wounds, namely the presence of necrotizing cellulitis. The same diagnosis could be made by ultrasonography as was revealed by necropsy. This case report provides valuable clarification about the use of ultrasound imaging of snakebites in cattle. The observation of snakebite scars is difficult in many cattle due to the thickness of their skin and the occurrence of dry bite cases. In addition to ultrasound, detailed blood tests and pathological findings should be included for more accurate diagnosis.

\section{References}

1. Warrell DA (2010) Snake bite. Lancet 375: 77-88.

2. Mirtschin PJ, Masci P, Paton DC, Kuchel T (1998) Snake bites recorded by veterinary practices in Australia. Aust Vet J 76: 195-198.

3. Goddard A, Schoeman JP, Leisewitz AL, Nagel SS, Aroch (2011) Clinicopathologic abnormalities associated with snake envenomation in domestic animals. Vet Clin Pathol 40: 282-292.

4. Langhorn R, Persson F, Ablad B, Goddard A, Schoeman JP, et al. (2014) Myocardial injury in dogs with snake envenomation and its relation to systemic inflammation. J Vet Emerg Crit Care (San Antonio) 24: 174-181.

5. Padula AM, Winkel KD (2016) Red-bellied black snake (Pseudechis porphyriacus) envenomation in the dog: Diagnosis and treatment of nine cases. Toxicon 117: 69-75.

6. Lenchner I, Aroch I, Segev G, Kelmer E, Bruchim Y (2014) A retrospective evaluation of Vipera palaestinae envenomation in 18 cats: (2006-2011). J Vet Emerg Crit Care (San Antonio) 24: 437-443.

7. Michal MT, Eran L (1999) Suspected Vipera palaestinae envenomation in three cats. Vet Hum Toxicol 41: 145-148.

8. Dickinson CE, Traub-Dargatz JL, Dargatz DA, Bennett DG, Knight AP (1996) Rattlesnake venom poisoning in horses: 32 cases (19731993). J Am Vet Med Assoc 208: 1866-1871.

9. Anlén KG (2008) Effects of bites by the European adder (Vipera berus) in seven Swedish horses. Vet Rec 162: 652-656.

10. Yeruham I, Avidar Y (2002) Lethality in a ram from the bite of a Palestine viper (Vipera xanthina palestinae). Vet Hum Toxicol 44: 26-27.

11. Mendez MC, Riet-Correa F (1995) Snakebite in sheep. Vet Hum Toxicol 37: 62-63.

12. Banga HS, Brar RS, Chavhan SG, Sandhu HS, Kammon AM (2009) Pathology of snake bite in a cow. Toxicol Int 16: 69-71.
13. Kanjanabuch T, Sitprija V (2008) Snakebite nephrotoxicity in Asia. Semin Nephrol 28: 363-372.

14. Yasunaga $\mathrm{H}$, Horiguchi $\mathrm{H}$, Kuwabara $\mathrm{K}$, Hashimoto $\mathrm{H}$, Matsuda $\mathrm{S}$ (2011) Short report: Venomous snake bites in Japan. Am J Trop Med Hyg 84: 135-136.

15. Nelson BK (1989) Snake envenomation. Incidence, clinical presentation and management. Med Toxicol Adverse Drug Exp 4: $17-31$.

16. Hakkarainen TW, Kopari NM, Pham TN, Evans HL (2014) Necrotizing soft tissue infections: review and current concepts in treatment, systems of care, and outcomes. Curr Probl Surg 51: 344-362.

17. Yen ZS, Wang HP, Ma HM, Chen SC, Chen WJ (2002) Ultrasonographic screening of clinically-suspected necrotizing fasciitis. Acad Emerg Med 9: 1448-1451.

18. Ishiyama D, Yamazaki A, Fujita M, Kondo A, Mizomoto T (2013) Bovine mastitis caused by Arcanobacterium pyogenes in Chiba prefectur. Japanese J Anim Hyg 39:1-7.

19. Merlino J, Siarakas S, Robertson GJ, Funnell GR, Gottlieb T, et al. (1996) Evaluation of CHROMagar Orientation for differentiation and presumptive identification of gram-negative bacilli and Enterococcus species. J Clin Microbiol 34: 1788-1793.

20. Lee YJ, Jeong YM, Lee HS, Hwang SH (2016) The Efficacy of Corticosteroids in the Treatment of Peritonsillar Abscess: A MetaAnalysis. Clin Exp Otorhinolaryngol 9: 89-97.

21. Pushker N, Tejwani LK, Bajaj MS, Khurana S, Velpandian T, et al. (2013) Role of oral corticosteroids in orbital cellulitis. Am J Ophthalmol 156: 178-183.

22. Caubet JC, Ponvert C (2014) Vaccine allergy. Immunol Allergy Clin North Am 34: 597-613.

23. Hifumi T, Yamamoto A, Morokuma K, Ogasawara T, Kiriu N (2011) Surveillance of the clinical use of mamushi (Gloydius blomhoffii) antivenom in tertiary care centers in Japan. Jpn J Infect Dis 64: 373-376.

24. Papich MG (2016) Ceftiofur hydrochloride. Saunders Handbook of Veterinary Drugs 139-140.

25. Gold BS, Barish RA, Dart RC (2004) North American snake envenomation: diagnosis, treatment, and management. Emerg Med Clin North Am 22: 423-443.

26. Oehler RL, Velez AP, Mizrachi M, Lamarche J, Gompf S (2009) Biterelated and septic syndromes caused by cats and dogs. Lancet Infect Dis 9: 439-447.

27. Chau CL, Griffith JF (2005) Musculoskeletal infections: ultrasound appearances. Clin Radiol 60: 149-159.

28. Stevens DL, Bisno AL, Chambers HF, Everett ED, Dellinger $P$, et al. (2005) Practice Guidelines for the Diagnosis and Management of Skin and Soft-Tissue Infections. Clin Infect Dis 41: 1373-1406.

29. Yassin AF, Hupfer H, Siering C, Schumann P (2011) Comparative chemotaxonomic and phylogenetic studies on the genus Arcanobacterium Collins et al. 1982 emend. Lehnen et al. 2006: proposal for Trueperella gen. nov. and emended description of the genus Arcanobacterium. Int J Syst Evol Microbiol 61: 1265-1274.

30. Ribeiro MG1, Risseti RM, Bolaños CA, Caffaro KA, de Morais AC, et al. (2015) Trueperella pyogenes multispecies infections in domestic animals: a retrospective study of 144 cases (2002 to 2012). Vet Q 35: 82-87.

31. Bancroft-Hunt JB, Weston JF, Munday JS (2010) Necrotising fasciitis in a bull due to infection with Arcanobacterium haemolyticum. $\mathrm{N} \mathrm{Z}$ Vet J 58: 260-264. 